\title{
NOTAS SOBRE A RECEPÇÃO DE HEGEL NA FRANÇA
}

\author{
Alexandre Cherulli Marçal \\ Mestrando em filosofia / UFF \\ Bolsista CNPq
}

\begin{abstract}
RESUMO: Trata-se de uma breve leitura sobre o sentido da recepção francesa de Hegel na França do século XX, pós-primeira guerra. Wahl, Koyré e Kojève são os autores em destaque e o ponto de partida para a compreensão de características centrais da influência hegeliana. Por fim, com Malabou e Zizek, oferecemos uma rápida interpretação para o sentido dessa recepção. $O$ saldo final são duas compreensões da negatividade que não se dialetizariam.
\end{abstract}

PALAVRAS-CHAVE: Hegel; recepção francesa; dialética, negatividade, cisão

Em Hegel e os gregos, Heidegger afirma que "no sistema especulativo, a filosofia chegou a sua plenitude, atingiu em outras palavras seu ponto mais alto e está, a partir dele, encerrada"1. Como a filosofia pode ter atingido seu ápice ao mesmo tempo em que resulta no próprio ocaso? O que há no pensamento hegeliano que desperta afetos tão diversos, desde entusiasmo e apreço até resistência e aversão? Sem dúvida, todo grande filósofo é passível de múltiplas interpretações e mal entendidos, porém talvez seja Hegel aquele que condensa as leituras mais extremadas. Afinal, com ele, alcançaríamos o ápice ou o ocaso do pensamento, ou haveria ainda outra via para sua realização? Veremos como a recepção de Hegel na França apresenta um modo próprio de resposta para essa questão.

Este texto é uma breve tentativa de compreensão do cenário francês da primeira metade do século XX no que diz respeito à recepção da filosofia hegeliana, especificamente no período pós-primeira guerra. Esperamos esboçar um panorama com algumas ideias centrais para, em seguida, problematizar pontos de ressonância que denotariam um traço comum aos estudos hegelianos

\footnotetext{
${ }^{1}$ HEIDEGGER, M. Hegel e os gregos, p. 208.
} 
desse período. Alguns autores são responsáveis por essa realização, dentre eles dois russos imigrados, Alexandre Koyré e Alexandre Kojève, e dois franceses, Jean Wahl e Jean Hyppolite. A filosofia hegeliana encontra um solo fértil para se enraizar em território francês através do ensino e das publicações desses pensadores, e seu legado estabelece um ponto de referência para os mais diversos e mais importantes intelectuais franceses do século XX que, de um modo ou de outro, se viram na necessidade de tomar posição quanto ao pensamento de Hegel. Dentre eles estão Bataille, Breton, Lacan, Sartre, Deleuze, Foucault e Derrida, para citar alguns. Pretendemos mostrar que a interpretação de Hegel na França tende a operar uma cisão intransponível dentro de seu próprio pensamento, e, deste modo, expor um impasse ao mesmo tempo em que aponta para sua superação. Nisso residiria tanto a fraqueza quanto a força do sistema hegeliano.

Em 1930, Koyré afirma que o estudo da influência hegeliana na França ainda estaria por ser realizado, pois, até então, essa influência era ainda "bastante difusa e bastante imprecisa" . De fato, o contexto filosófico francês do século XIX e do início do século XX muito dificilmente incluíam Hegel no hall de pensadores importantes. A virada e 0 início do século $X X$ foram predominantemente marcados pelo espiritualismo de Henri Bergson e pelo racionalismo neo-kantiano de Leon Brunschvicg, ambos relacionados à herança cartesiana. Nesse meio, o pensamento hegeliano era ou rejeitado ou mal conhecido: as fontes para seu estudo eram em sua maioria de segunda mão, sobretudo vindas de compêndios franceses sobre filosofia alemã, e não existiam traduções para as principais obras do filósofo. Dotado de um estilo e de uma linguagem de difícil compreensão, Hegel não era reconhecido em nenhum dos flancos francófonos, sendo demasiadamente intrincado para os debates em torno da consciência e do ego e excessivamente hermético para o rigor científico e matemático da época.

Nos primeiro trinta anos do século $X X$, apesar da primeira guerra, presencia-se na França um crescente interesse pelo pensamento alemão,

\footnotetext{
${ }^{2}$ KOYRÉ, A. Estudos de história do pensamento filosófico, p. 235.
} 
impulsionado pela novidade da fenomenologia husserliana e acompanhado por Karl Jaspers na psiquiatria e por Heidegger na filosofia. No início do século XX, a obra de Husserl começa a ganhar relevância com a crise da matemática e do abalo das fundamentações das ciências. Nas Meditações cartesianas, Husserl problematizada diretamente a herança cartesiana em vista da relação entre consciência e mundo: o ego só existe em relação ao outro e, partindo desse debate, a fenomenologia se mostra um adversário à altura do racionalismo e do cientificismo da época. Sob o signo dessa revolução filosófica chamada fenomenologia foi-se necessário retomar sua homônima moderna, a fenomenologia hegeliana. À luz da fenomenologia transcendental de Husserl e das leituras de Ser e tempo de Heidegger, Hegel passa a ser tratado como um filósofo contemporâneo, valorizado nos mais avançados círculos intelectuais da época, e sua ciência da experiência da consciência se torna um modo inovador de compreensão da realidade humana. Assim, nascia na França a "geração dos três $\mathrm{H}^{\prime \prime}$ (Husserl, Heidegger e Hegel).

O primeiro grande responsável pela recepção de Hegel na França pós primeira guerra foi Jean Wahl com o livro Le malheur de la conscience dans la philosophie de Hegel (1929). No artigo "Relatórios sobre o estado dos estudos hegelianos na França", escrito um ano após o lançamento do livro de Wahl, o grande elogio tecido por Koyré a obra de seu colega ilustra a efervescência do momento e adianta a inegável influência que ela exerceria ao hegelianismo insurgente: "O belo livro que ele [Jean Wahl] consagrou ao estudo da Consciência infeliz na filosofia de Hegel é um esforço para retomar, por detrás e por debaixo das fórmulas abstratas do sistema, a vida e o sangue que o nutrem, e de que elas são apenas pálidas e longínquas expressões" ${ }^{\prime 3}$. Seguindo Koyré, podemos dizer que a leitura de Wahl parte de três pressupostos principais: a importância das intuições encontradas nos escritos de juventude de Hegel; a questão religiosa como problema fundamental a toda obra hegeliana; a consciência infeliz como figura idiossincrática que constitui a história da consciência enquanto tal e o sujeito. Eis que, reconhecendo no ser humano a

\footnotetext{
${ }^{3}$ KOYRÉ, A. Estudos de história do pensamento filosófico, p. 251.
} 
negatividade dilaceradora constitutiva da consciência infeliz, Wahl acentua um lado trágico, dramático e vivo do pensamento hegeliano e propõe uma leitura fenomenológica da lógica, o que termina por: "contribuir para dar ao hegelianismo francês uma coloração existencial, senão existencialista" ${ }^{\prime 4}$.

Ao invés de propormos um julgamento sobre o "correto" e o "errado" das leituras francesas do texto hegeliano, partimos de suas interpretações para compreender o saldo peculiar que resulta do enfrentamento com Hegel. Aqui, destacaremos dois, um em consequência do outro. $O$ primeiro já pode ser depreendido da obra de Jean Wahl, e foi bem enunciado por Jarczyk e Labarrière: "A história de um hegelianismo "à francesa", para apreendê-lo numa fórmula sem dúvida simplista, abre um caminho da existência do sistema ao sistema da existência, antes que esses dois termos se conjuguem sob a exigência de uma pressuposição recíproca" ${ }^{5}$. O segundo é uma contribuição de Malabou: "os comentaristas de Hegel transformam sua dialética em uma "esquizologia" (do grego skizo, cindir, partir), lógica de oposições irreconciliáveis. O processo dialético não seria então legível senão a luz do seu impensado: um discurso da abertura [fente], ou um da divisão [clivage]"6. Esperamos mostrar porque essas duas visões da recepção francesa de Hegel fazem sentido e o que elas significam para a compreensão da filosofia hegeliana.

Aos dezessete anos, Koyré estudou com Husserl na universidade de Göttingen e também acompanhou cursos de Bergson e Brunschvicg em Paris. Socialista convicto, ele chegou a ser preso por atividades políticas, participou das atividades revolucionárias de 1917 e combateu no front russo na Grande Guerra. Em 1919, Alexandre Koyré emigra definitivamente para França onde, anos mais tarde, após a defesa de uma tese de filosofia sobre Jacob Boehme, viria ocupar o cargo de diretor da V Seção da École Pratique de Hautes Études (EPHE), dedicada ao estudo da história das ideias religiosas. Com uma história

\footnotetext{
${ }^{4}$ JARCZYK, G. \& LABARRIÈRE, P-J. De Kojève à Hegel: 150 ans de pensée hégélienne en France, p. 27.

${ }^{5}$ JARCZYK, G. \& LABARRIÈRE, P-J. Kojève à Hegel: 150 ans de pensée hégélienne en France, p. 20.

${ }^{6}$ MALABOU, C. Negativos de la dialéctiva. Entre Hegel y Heidegger: Hyppolite, Koyré, Kojève, p. 172.
} 
de vida agitada e detentor de grande erudição, ele se torna um importante estudioso da história das ciências e das ideias científicas, sempre as relacionando com concepções filosóficas e religiosas subjacentes.

No que diz respeito aos estudos hegelianos, Koyré ministrou cursos sobre o pensamento religioso de Hegel, e como uma celebração do centenário da morte do alemão redigiu três importantes artigos posteriormente publicados no livro Estudos de história do pensamento filosófico (1961): já mencionamos o primeiro artigo que versa sobre o estatuto dos estudos hegelianos na França; o segundo trata sobre a linguagem hegeliana e defende que a estranheza que ela manifesta provém da incorporação de uma terminologia advinda da linguagem viva do cotidiano, o que não poderia ser diferente para aquele que pretende mostrar a concretude e a historicidade da razão e do Espírito; já o terceiro é uma leitura dos textos de lena, período de juventude de Hegel que antecede a Fenomenologia do espírito (1807).

Nesse último artigo, declaradamente seguindo as intuições de Jean Wahl, Koyré afirma haver uma cisão entre a trágica obra de juventude de Hegel, do "verdadeiro Hegel" ${ }^{17}$, e a frieza sistemática dominante na Lógica e na Enciclopédia. ${ }^{8}$ Essa observação aponta para um antagonismo entre o método dialético e o sistema, isto é, entre a experiência da consciência e a lógica do sistema. Os esforços de Koyré se voltam para a compreensão dessa fratura. De certo modo, a dificuldade perseguida ao longo do texto de Koyré é entender como Hegel pode: "fazer um sistema ao mesmo acabo e móvel" reconhecendo a identidade da lógica com a história como o fundamento da dialética hegeliana, como conceber o "mistério sagrado" ${ }^{10}$ que é a relação entre finito e infinito, do temporal e com eterno, do tempo histórico com o conceito? Teria Hegel praticado o método dialético sem nos contar seu "segredo", sem revelar os princípios de seu método?

\footnotetext{
${ }^{7}$ KOYRÉ, A. Estudos de história do pensamento filosófico, p. 152.

8 "Um Hegel humano que vibrava, que sofria. Um Hegel que tinha um lugar no movimento espiritual da época e não apenas no quadro, cronológico e sistemático dos sistemas". In: KOYRÉ, op. cit., p. 151.

${ }^{9}$ KOYRÉ, A. Estudos de história do pensamento filosófico, p. 164.

${ }^{10}$ KOYRÉ, A. Estudos de história do pensamento filosófico, p. 168.
} 
Segundo Koyré: "a origem, o fundamento da dialética hegeliana está [...] na relação do finito e do infinito"11. Portanto, o destino do método dialético segue da compreensão dada à relação entre esses dois opostos: eles seriam constituídos por uma "inquietude" inerente que os conecta numa relação recíproca de negação e afirmação de um pelo outro. Tal "inquietude aniquiladora" os torna polos indissociáveis vinculados numa solidariedade estrutural entre finito, infinito e temporalidade. ${ }^{12}$ Se o infinito estabelece uma relação de negação com o finito na qual o infinito se afirma como existente a partir do ser daquilo que ele aniquila, então a relação dialética "dramática" do infinito e do finito resulta na essência mesma da finitude. Isso permite a Koyré afirmar a identidade entre o eterno e o temporal como o fundamento da existência, fundamento do próprio tempo histórico que, para o russo, é entendido como tempo humano. Haveria uma "primazia ontológica" do "agora", do instante presente que constitui a temporalidade, pois é a partir da negação do agora, do imediato, do "imediado", que se temporaliza o porvir e, em seguida, em vista do primeiro, o passado. Eis que o tempo hegeliano é o tempo do ser humano:

\footnotetext{
"ser que, partindo do presente, o renega, procurando se realizar no porvir, que vive para o porvir encontrando nele, ou pelo menos ali buscando a sua "verdade", ser que só existe nessa transformação contínua do porvir no agora, e que deixa de existir no dia em que não existe mais porvir, onde nada mais resta por vir, onde tudo já veio, onde tudo já está "completo". E é porque o tempo hegeliano é humano que ele é também dialético, assim como é porque ele é uma coisa e outra, que ele é essencialmente um tempo histórico." ${ }^{13}$
}

Destacamos aqui dois pontos importantes: o tempo dialético, que é o tempo hegeliano, só adquire sentido para Koyré quando pensado como tempo do ser humano, ser finito infinitamente inquieto que estabelece uma relação negativa com o presente através da antecipação do futuro; se a verdade da dialética é o novo, o porvir, então o dia que não há mais porvir é a morte. Nele, a identidade da história e da lógica, do temporal e do eterno, não porta mais a

\footnotetext{
${ }^{11}$ KOYRÉ, A. Estudos de história do pensamento filosófico, p. 169.

12 "A inquietude é o fundamento do ser. O finito e infinito se perseguem e se abismam um no outro; eles só são um com relação ao outro. [...] a análise dialética do infinito e do finito nos esboça os quadros do instante e do tempo". KOYRÉ, A. Estudos de história do pensamento filosófico, p. 170-171.

${ }^{13}$ KOYRÉ, A. Estudos de história do pensamento filosófico, p. 181.
} 
fruição do tempo humano, mas, solapando a diferença, ela detém o tempo e o expõe como uma sucessão de momentos, ordem linear, fria e sem vida que compõe a filosofia da história. O problema é: o significado da história não emerge senão da anulação do sentido da história, isto é, pensar a história significa deter a história, negar o movimento que a tornou possível. Por isso, segundo Koyré, essa morte que está desde sempre presente no sistema como negatividade, que é o conceito absoluto e que aparece como a detenção do tempo revela o "fracasso do esforço hegeliano", pois:

\begin{abstract}
só o caráter temporal do tempo torna possível uma filosofia da histórica; mas ao mesmo tempo o caráter temporal da dialética a torna impossível. [...] A síntese é imprevisível: não podemos construíla; só podemos analisá-la. A filosofia da história - e por isso mesmo a filosofia hegeliana, o "sistema" - só seria possível se a história estivesse terminada; ${ }^{14}$
\end{abstract}

Após a consideração de características centrais do enfrentamento de Wahl e de Koyré com a filosofia hegeliana, a interpretação oferecida por Kojève não causa grande estranhamento. Encontramos nela a radicalização de alguns aspectos do pensamento de seus contemporâneos, agora apresentados sob uma forma mais acessível e mais peculiar, impulsionada por um discurso eloquente que lotaria o auditório da $5^{\text {a }}$ seção da EHPE. ${ }^{15}$

Como estudante na universidade de Heidelberg, Kojève frequentou cursos Jaspers e Husserl, e iniciou suas leituras de Hegel, porém sem êxito. Em 1926, o russo se instala definitivamente em Paris e se torna amigo de seu compatriota Koyré, e, em seguida, tornar-se seu ouvinte. Com a saída de Koyré da EPHE no final do ano de 1933, Kojève propõe substituir o amigo, dando continuação ao ensino sobre a filosofia de Hegel já ministrada pelo conterrâneo. De 1933 a 1939 ele ministrou seminários anuais sobre a Fenomenologia do espírito. Como que seguindo o exemplo de Jean Wahl, Kojève sobreinterpreta uma passagem da FdE que passa a ser utilizada como chave de leitura para todo o restante da obra hegeliana. Ao invés da parte $B$ do capítulo IV da FdE, Kojève escolhe a parte $\mathrm{A}$ do mesmo capítulo: "A dialética do

\footnotetext{
${ }^{14}$ KOYRÉ, A. Estudos de história do pensamento filosófico, p. 193.

${ }^{15}$ A importância de Kojève para o hegelianismo francês é enorme e, aqui, não podermos dar a ela a interpretação detalhada que merece. Portanto, procuraremos apenas destacar alguns pontos de ressonância que o conecta aos outros autores e ao intuito principal do presente texto.
} 
senhor e do escravo" se torna o texto fundamental da interpretação kojèviana. Entretanto, é em Koyré que ele afirma encontrar os elementos que tornam possível sua interpretação da Fenomenologia de Hegel. ${ }^{16}$ Tal como seu amigo, Kojève reconhece uma primazia ontológica ao tempo verdadeiramente dialético, isto é, o tempo histórico/humano oposto à qualquer tempo biológico ou cósmico. Esse tempo se constitui do futuro para o passado: o futuro porta a negatividade que coloca o tempo em movimento.

Se a partir da elaboração de Koyré do tempo dialético como tempo histórico/humano já é possível compreender a Fenomenologia do espírito como uma antropologia, Kojève encontra no conceito de desejo do capítulo IV a possibilidade de levar essa leitura às últimas consequências. "O movimento gerado pelo futuro é o movimento que nasce do desejo"17. Para Kojève, o desejo é "presença de uma ausência" que constitui a essência do ser humano enquanto ser histórico e, entendendo o desejo como ação, o ser humano é "projeto", expressão da pura negatividade do porvir que nega toda realidade dada. Desse modo, Kojève opera uma cisão intransponível entre natureza e cultura, entre realidade natural e realidade humana, fundando um dualismo ontológico baseado na noção de desejo humano que fará história na tradição francesa de recepção de Hegel.

$\mathrm{Na}$ medida em que a linguagem é compreendida como discurso conceitual, trabalho do conceito, ela também atua a partir da negação da realidade dada, pois nega o ser-aí da coisa e a apresenta onde ela não está. Kojève defende a identidade entre o conceito e o tempo como a possibilidade da existência do ser humano como ser histórico e livre, entretanto, assim como Koyré ele provocará um curta-circuito na filosofia hegeliana afirmando o fim da história como imprescindível ao sistema. Para Kojève, a verdade só existiria após o fim da história, após a realização completa do tempo no conceito. Eis que ele forja a figura do Sábio como aquele que se limita a compreender a realidade sem negá-la. Assim, Kojève parece oferecer uma resposta - meio burlesca e um

\footnotetext{
${ }^{16}$ A respeito do artigo de Koyré que acabamos de interpretar, Kojève afirma: "[é um] artigo decisivo, fonte e base da minha interpretação da Fenomenologia" In: KOJÈVE, A. Introdução à leitura de Hegel, p. 347.

${ }^{17}$ : KOJÈVE, A. Introdução à leitura de Hegel, p. 348.
} 
tanto escatológica - para a detenção do tempo prenunciada por Koyré: o saber absoluto é pensado em termos do final dos tempos, e somente o Sábio poderia contemplá-lo e compreendê-lo efetivamente, sem nada negar.

Retomando a fórmula de Jarczyk e Labarrière citada anteriormente, poderíamos dizer que Wahl, Koyré e Kojève percorrem o caminho da existência do sistema ao sistema da existência, porém, ao chegarem lá, percebem que os dois termos de fato possuem uma pressuposição recíproca que, em última instância, se sustenta numa ruptura, num antagonismo intransponível. A negatividade que vivifica o ser humano como ser histórico e temporal é a mesma que, do ponto de vista do absoluto, freia o caráter negativo do tempo e do desejo. Portanto, podemos afirmar que o pensamento deles se depara com o mesmo paradoxo: reunir sem contradizer as significações históricas e lógicas da negatividade hegeliana.

Segundo Malabou, esse antagonismo encontrando em Hegel provém de duas significações irreconciliáveis da negatividade: 1) negatividade fundadora da finitude originária e inquieta do ser humano e do presente, ou seja, uma compreensão ontológica da negatividade como transcendência; 2) negatividade estritamente lógica que, do ponto de vista do saber absoluto, pressupõe a atemporalidade do conceito. ${ }^{18}$ Tudo se passa como se, voltando à negatividade contra si mesma, os interpretes franceses de Hegel formulassem uma fratura, um curta-circuito, um antagonismo no cerne da filosofia hegeliana que não pode ser dialetizado, "suprassumido" ou resolvido. Portanto, o "segredo" de Hegel não pode ser compreendido senão sob o reconhecimento de um cisma, de um núcleo fraturado e estranho nunca pensado que dá origem a toda processualidade dialética e que, no entanto, não é ele mesmo dialetizável. É nesse sentido que Malabou afirma que esses autores oferecem uma leitura "esquizológica" de Hegel. Deste modo, parece que seus trabalhos contribuíram para fazer surgir um tipo de aproximação da negatividade dialética que se encontra no coração de leituras mais recentes de Hegel. Concordamos com Zizek quando ele afirma que:

\footnotetext{
${ }^{18}$ Cf. MALABOU, C. Negativos de la dialéctiva. Entre Hegel y Heidegger, p. 165/171.
} 
Com os interpretes de Hegel do século XX [...], essa contradição entre - "lógico" e o "histórico" adquire uma sustentação profundamente radical: tentam mostrar uma faceta ontológica fundamental que é tanto a fonte dialética da sistematização de Hegel quanto, ao mesmo tempo, a traição promovida por essa sistematização. ${ }^{19}$

Haveria em Hegel um pensamento da finitude, da diferença e do porvir ou tudo se conclui na clausura absoluta do Sistema e na estabilidade do presente perpétuo? A filosofia hegeliana está desde sempre já fadada ao fim pelo mesmo motivo que se torna viva? Estaria Hegel alienado, e a dialética impotente frente às figuras duais da cisão que ela não pode assumir? Para Zizek, a confusão reside na própria noção de automediação com que a dialética hegeliana trabalha: "tensão interna entre pulsão sistemática do conceito nocional de automediação (ou suprassunção) e um projeto ontológico mais original" $^{\prime 20}$.

Afinal, um pensamento construído por meio de oposições irreconciliáveis pode ser uma dialética no sentido hegeliano? Ou a verdade do sistema hegeliano não estaria na própria cisão, e a contradição e a automediação o modo pelo qual a negatividade nomeia esse ponto limite, esse "segredo" que não cessa de não se revelar? Esperamos continuar esse assunto numa nova ocasião.

\section{Bibliografia}

HEIDEGGER, M. "Hegel e os gregos". Tradução: Ernildo Stein. In: HEIDEGGER, M. Conferências e escritos filosóficos. São Paulo: Abril Cultural, 1979.

JARCZYK, G.; LABARRIÈRE, P-J. De Kojève à Hegel: 150 ans de pensée hégélienne em France. Paris: Albin Michel, 1996.

KOJÈVE, A. Introdução à leitura de Hegel. Tradução: Estela dos Santos Abreu. Rio de Janeiro: Ed. UERJ, 2002

KOYRÉ, A. Estudos de história do pensamento histórico. Tradução de Maria de Lourdes Menezes. 2. Ed. Rio de Janeiro: Forense, 2011.

\footnotetext{
${ }^{19}$ ZIZEK, S. "Hegel X Heidegger", p. 1. Ps: Mais adiante, Zizek deixa claro que está se referindo especificamente aos interpretes franceses de Hegel pós-primeira guerra (Kojève, Koyré, Hyppolite).

${ }^{20}$ ZIZEK, S. "Hegel X Heidegger", p. 1.
} 
MALABOU, C. "Negativos de la dialéctica. Entre Hegel y Heidegger: Hyppolite, Koyré, Kojève". Tradução: Javier Pavez. In: Revista pensamiento político, n. 5, p. 158-174, julho 2014.

ŽlŽEK, S. Hegel versus Heidegger. E-flux journal, n.32, fev. 2012. 